\title{
Desarrollo y gestión social del riesgo: ¿una contradicción histórica?1
}

\author{
Javier Enrique Thomas Bohórquez²
}

\begin{abstract}
RESUMEN
Desde una perspectiva crítica se revisan aquí algunas de las ideas centrales que han dado origen al paradigma del "Desarrollo" y se establecen los vínculos causales entre este y la generación de situaciones de riesgo y su eventual evolución en desastres. Posteriormente, se esbozan ciertos elementos que permitirían, en el marco de una perspectiva territorial y tomando como referente la gestión pública en América Latina, implementar una política de Gestión Social del Riesgo (GSR). Los aportes de este trabajo radican en la intención de hacer evidente la necesaria y no suficiente aún articulación entre objetivos y estrategias de Planeación Territorial y Gestión del Riesgo, bajo una misma política de Planificación: La GSR, entendida esta como el proceso institucional y social que permite la convergencia de políticas, actores, estrategias y acciones, alrededor de la eliminación de las condiciones y de la reducción de los elementos generadores de vulnerabilidad de las comunidades ante eventos potencialmente destructores.
\end{abstract}

Palabras clave: Desarrollo, Gestión Social del Riesgo, vulnerabilidad, planeación territorial.

\begin{abstract}
Following the arguments presented by LA RED related with disaster prevention, this article reviews some of the central ideas of "Development", to establish causal relationships between this and the generation of hazardous situations in communities and their possible evolution to disaster. Then, we outline some elements that would allow, within a territorial perspective and taking public management in Latin America as a referent, the implementation of an Integrated Risk Management policy. The contributions of this work relies on the intention to make it clear how necessary, and yet insufficient, it is for the articulation between objectives and strategies of Territorial Planning and Risk Management to be under a single policy of Planning: The Social Risk Management (GSR), defined as an institutional and social process that enables the convergence of policies, actors, strategies and actions, around the elimination and reduction of conditions and factors that generate vulnerabilities in communities upon potentially destructive events.
\end{abstract}

Key words: Development, Social Risk Management, vulnerability, territorial planning.

1 Artículo recibido el 12 de noviembre de 2009, aceptado el 13 de octubre de 2010 y corregido el 20 de octubre de 2010.
2 Departamento de Geografía, Universidad del Valle (Colombia).E-mail: jenthobo@univalle.edu.co 
A pesar de matices y particularidades propias de su momento histórico y de las corrientes y postulados políticos y económicos que defiendan, Cuny (1983), Blaikie et al. (1996), Davis y Cory (1996), Quarantelli (1996), Hewitt (1996), Wilches (1998), CEPAL y BID (2000), Kohler et al. (2004), Chaparro y Renard (2005) y Lavell $(2000 ; 2008)$ coinciden en plantear los desastres como temas no resueltos del desarrollo; en general, afirman que las condiciones sociales, políticas, económicas e institucionales, resultantes de un modelo de desarrollo impuesto en el planeta de forma unilateral y hegemónica, hacen proclives, en lo local, la generación de condiciones favorables para la ocurrencia de desastres. Si bien esta idea es cada vez más generalmente aceptada, pareciera también que las evidencias de esta afirmación aún no son lo suficientemente contundentes para que los tomadores de decisiones incorporen estas como herramientas de juicio para modificar las formas prácticas en que dicho modelo de desarrollo se implementa en sus escenarios locales. No se pretende aquí establecer una relación mecánica y lineal entre pobreza y desastres o concebirlos como sinónimos; lo que se busca es ahondar en el papel que juega el modelo de desarrollo y la forma particular en que este se implementa en los países subdesarrollados, en la configuración de situaciones de riesgo para la población. Para ello se abordarán, inicialmente, algunas ideas generales sobre el desarrollo, su discurso y prácticas (Comeliau, 1992; Escobar, 1998; Rist, 2002), así como su vinculación con potenciales desastres (Anderson \& Woodrow, 1989; Hewitt, 1996; Davis y Cory, 1996; Lavell, 2000), para luego establecer las nociones que sustentan la Gestión Social del Riesgo y su convergencia con la Planificación Territorial.

\section{Desarrollo y riesgos. Ideas para un debate}

Desde la segunda década del siglo pasado y a partir del célebre discurso del presidente de los Estados Unidos, Harry Truman (20 de enero de 1949), se ha venido planteando la necesidad de definir condiciones que garanticen el desarrollo de los pueblos, independientemente de su localización geoastronómica y de las implicaciones geopolíticas de ello. Esto, que debería encerrar fines altruistas en todos los casos, no obstante ha demostrado, a lo largo de estos años, que para muchos sus resultados prácticos distan bastante de ello, no solo por dificultades tecnológicas y culturales, sino, fundamentalmente, materiales, ideológicas y políticas. Consecuentemente, se han generado dos caras de la misma moneda, por un lado, aquellos países que cuentan con estándares de crecimiento y desarrollo importantes, y de otro, los que habiendo contado con procesos históricos y culturales diferentes, sus actuales resultados los ponen en significativas condiciones de retraso en relación con los estándares definidos en y por los primeros (Rist, 2002); ello, según esta lógica, los hace subdesarrollados. Desde este lugar, este par antagónico complementario (Morin, 1986), desarrollo/subdesarrollo, define la realidad económica y política del mundo contemporáneo.

A partir de este discurso muy rápidamente se fue consolidando y haciendo realidad, en y para aquello que se conoció como el Tercer Mundo, el concepto de desarrollo que estaba vinculado con los referentes establecidos desde los países denominados desarrollados: ingresos económicos y acceso a bienes materiales; es decir, pobreza y restricciones a condiciones materiales, que definen determinado nivel de vida occidental, se convirtieron en los únicos indicadores para establecer los límites entre desarrollo y subdesarrollo. La estadística moderna estableció el sustento científico y disciplinar que soporta el método comparativo utilizado. Los aspectos sociales y políticos, parte integral de la vida y la cotidianidad del individuo, se consideraban como resultado mecánico de los económicos (Comeliau, 1992); a medida que estos últimos aumentaran, en algún momento los primeros también lo harían; sin embargo, ellos de por sí no fueron objeto de interés ni de estudio particular.

En consecuencia, independientemente de los referentes conceptuales asumidos y de la tendencia de desarrollo elegida ${ }^{3}$, se imple-

\footnotetext{
3 Dentro de la Economía del Desarrollo que se sustenta en la Teoría Clásica del Crecimiento, tres fueron las tendencias más importantes: la del Crecimiento equilibrado de Nurkse, la Economía dual de Lewis y la teoría de Centro-periferia de la CEPAL. Para
} 
mentó en las diversas economías nacionales la fórmula que inmodificablemente garantizaría, para los países al margen de él, el tan anhelado desarrollo económico: a) acumulación de capital (ahorro-inversión); b) industrialización-urbanización, entendida esta última como aquella que definía el clima favorable y posible para la primera; c) planeación del desarrollo; y d) ayuda externa (endeudamiento). Estas medidas concebidas en conjunto serían la clave para superar las dificultades circulares y estructurales que presentan los países subdesarrollados: baja capacidad de ahorro, por tanto baja inversión y bajo crecimiento, incipiente industrialización y alta mano de obra destinada al sector rural, baja capacidad de incidencia en el mercado internacional por producción de bienes primarios y consecuentemente alta dependencia del mercado externo (Escobar, 1998).

Esto trajo, como hecho inevitable para estas áreas, el "crecimiento de transformación cuantitativa, basado en la utilización de caudales cada vez mayores de energía y materias primas" (Goodland et al., 1997: 14) y con ello consecuencias nefastas no solo a la sociedad y su entorno, sino para la creación de condiciones inseguras a importantes porcentajes de la población, propicias para la construcción progresiva de vulnerabilidades (Blaikie et al., 1996) y posteriores desastres; un modelo de empresa que desconoce $y / o$ niega los impactos y degradaciones ambientales de un proceso voraz de apropiación selectiva de los recursos naturales y de su posterior transformación fabril (incluidos los desechos del mismo); una sociedad de consumo, que reconoce y privilegia, como una expresión de poder, a quien más ostenta y derrocha recursos y productos; una población dispuesta a obtener a cualquier precio los estándares de vida propios del consabido desarrollo, sin importar los costos ecológicos, sociales o culturales de ello; un crecimiento urbano reactivo a las dinámicas propias de la lógica industrial, carente de procesos de planificación y de un proyecto de ciudad ${ }^{4}$; una

adentrarse en ellas, ver Nurkse (1961), Lewis (1979) y CEPAL (1951).

4 Según la "Unidad de Gestión del Riesgo y los Desastres" (CNUAH, 2001), rama del Desarrollo Urbano de la EIRD, en el decenio de 1990, entre educación más vinculada con la producción, la eficiencia y la competitividad económica, que con la construcción de valores que reconozcan, resignifiquen y potencien la construcción colectiva (comunidad) o que permita la sensibilización frente a problemas sociales de diversa índole y escala; y de manera especial, la convicción generalizada, en la clase política dirigente, las burguesías nacionales, la sociedad civil y la población en general, de que el único camino posible por recorrer era la "desarrollalización del tercer mundo" (Escobar, 1998) a través de la connatural fórmula para ello: el desarrollo occidental, hecho a la occidental.

Estas, como causas estructurales de las vulnerabilidades, se expresaron en condiciones perjudiciales para la población: incremento y concentración poblacional en áreas urbanas en progresivas situaciones de precarización (en tipologías, técnicas y materiales constructivos y en acometidas de servicios públicos domiciliarios) y baja habitabilidad (condiciones geológicas, geotécnicas y geomorfológicas del suelo, limitada oferta urbana y equipamientos colectivos); restricciones para el acceso equitativo al suelo urbano a la población en general y cierto control de la tierra, de parte de algunos y, por tanto, localización de las comunidades marginadas en zonas peligrosas (Thomas, 2008); deforestación y degradación de cuencas hidrográficas y laderas e incremento de probabilidades de aparición de fenómenos de remoción en masa; marginamiento de la toma de decisiones políticas; exclusión a importantes sectores de la población a procesos de escolarización, cualificación y capacitación y a redes de seguridad social; escasa posibilidad de ascenso social y mejoramiento de la calidad de vida, entre otros.

Las cifras que respaldan estas afirmaciones son contundentes, el Banco Mundial, (2000) calcula que "el 97\% de las muertes relacionados con los desastres naturales cada año ocurren en los países en desarrollo $y$, aunque es menor en cifras absolutas, el

el $60 \%$ y el $70 \%$ de la urbanización ocurrió sin planificación; a menudo en áreas próximas a zonas industriales conocidas por su alta sismicidad o predisposición a las inundaciones. 
porcentaje de las pérdidas económicas en relación con el Producto Nacional Bruto de los países en desarrollo supera en mucho al de las naciones desarrolladas" (Banco Mundial, 2000: 170). En el mismo sentido, la EIRD (2001) establece que "de los 49 países menos desarrollados, al menos seis de ellos han venido sufriendo entre dos y ocho desastres importantes por año durante los últimos 15 años, con secuelas a largo plazo para el desarrollo humano. Estas cifras serían mucho mayores, el doble o más, según algunos expertos, si se pudieran contabilizar también las consecuencias de los muchos desastres menores no registrados que provocan pérdidas significativas en el plano local o comunal" (EIRD, 2001: 5).

Lavell (2008), adicionalmente, establece un elemento que resulta importante para la comprensión de agentes causales y mecanismos funcionales, pero en especial, de posibilidades de intervención y gestión del riesgo, y es el hecho de que cada modelo de desarrollo construye su propio modelo de riesgo. Por ejemplo, el tipo de desarrollo propio de una política de sustitución de importaciones; donde se busca crear y fortalecer una industria nacional para mercados internos; exige, de una parte, la instalación y consolidación de empresas con sustento y arraigo local y con una proyección temporal importante en el territorio, y de otra, la creación de condiciones particulares que garanticen que la población (los potenciales consumidores) tenga cierta estabilidad laboral y capacidad de compra, y ello va acompañado, por supuesto, de empleo y seguridad laboral y social. En contraste, un modelo de apertura y liberalización comercial; en función de mercados internacionales y de una alta competitividad de los procesos incorporados, agenciado y desarrollado fundamentalmente por grandes trasnacionales; no solo desarrolla prácticas más agresivas en la explotación y utilización de los recursos naturales locales, sino que, debido al carácter migratorio de los capitales, define dinámicas territoriales internas de alta inestabilidad y condiciones de restricciones e inseguridad laboral y social a los trabajadores.

Cada uno de los modelos mencionados genera condiciones particulares para la creación de vulnerabilidades ante amenazas naturales, y en consecuencia, de riesgos; en el primer caso, las condiciones de riesgo dependen más de la acomodación local de las fuerzas generadoras del desarrollo (de más fácil intervención) y en el segundo, están más en función de la localización global de factores productivos, la posición estratégica que se ocupe en los nichos de mercado y en la presión política y comercial que se pueda ejercer en los mercados internacionales (de mucho más difícil control e intervención local).

Son las relaciones sociales de producción, entonces, las que hacen que sectores específicos de la sociedad presente condiciones particulares de vulnerabilidad y creen, a su vez, espacios riesgosos para ellos y sus actividades. En analogía a lo que plantea Sen (1991), frente a las hambrunas que sufre un porcentaje importante de la población en África, podríamos decir que, tal como las hambrunas modernas nunca son cuestiones de absoluta escasez de comida dentro del sistema alimentario mundial, los desastres tampoco responden a la capacidad de devastación intrínseca de un evento natural. Unas y otros giran en torno a lo que este autor ha descrito como los derechos de acceso y las capacidades y habilitación para la autogestión (Sen, 1991) de aquellos más propensos a resultar afectados; Ilámese hambruna o desastre, según cada caso.

En otras palabras, el nivel de daño sufrido por la población se relaciona significativamente con sus condiciones antes, durante y después del evento en particular y no simplemente por las características de este (tipo, magnitud, localización, frecuencia, entre otros). Es decir, los desastres, como expresión material del riesgo, se configuran en el día a día, en las circunstancias particulares (socioeconómicas, políticas e institucionales) en que la sociedad, previamente y en condiciones progresivas, hace vulnerables a las comunidades ante los eventos potencialmente destructivos; por tanto, los desastres además de no ser naturales, "no ocurren, se manifiestan" (Calderón, 2001: 17).

Incluso, yendo un poco más allá, es fundamental reconocer que el papel que juegan Estado y Sociedad alrededor de las condiciones que definen la vulnerabilidad social de las poblaciones, es esencial. La concepción 
y percepción social del riesgo y la forma como la vulnerabilidad se materializa en una política pública, resulta esencial para la generación o no de divergencias y contradicciones entre las prioridades económicas de la sociedad y las condiciones seguras de las comunidades; preferencias económicas pensadas, por lo regular, en función de los sectores más dinámicos de las economías nacionales, mejor preparados y resguardados frente a la ocurrencia de eventos extremos, y de donde, no necesariamente a partir de ellos, se producen condiciones seguras para la mayoría de la población, y de forma preponderante, para los sectores marginales y excluidos. Así entendido, se expresa la falsa premisa de que el costo económico de la protección humana riñe con las metas de crecimiento económico y desarrollo social para todos. Es muy cierta entonces la afirmación de Hewitt (1996) de que "la distribución de daños en desastres refleja principalmente el orden social que produce, reproduce y regula las actividades humanas" (Hewitt, 1996: 11), o, tal como lo aseveran Susman et al. (1983), la vulnerabilidad es el grado en que las diferentes clases sociales están diferencialmente en riesgo.

En este sentido, una concepción del riesgo asida fundamental o exclusivamente al papel establecido por el evento natural, desplaza el diseño de políticas públicas hacia la construcción de obras de infraestructura orientadas a disminuir el impacto del evento y no a identificar las condiciones sociales, políticas, económicas o institucionales que hacen a las comunidades vulnerables ante ese evento en particular. Dicho de otra forma, la concepción social de riesgo y el análisis de la vulnerabilidad de la población tocan necesariamente el ámbito político y el equilibrio local de fuerzas y distribución de recursos, donde surgen forzosamente asuntos estratégicos y sensibles de los intereses de los grupos poderosos; "mientras que la introducción, por ejemplo, de un sistema de alerta contra ciclones es un proceso políticamente neutral, probablemente no sea éste el caso de muchos de los métodos para reducir la vulnerabilidad. Los controles de uso del suelo para evitar la urbanización de laderas y los patrones legales de propiedad de la tierra para permitir a las familias mejorar la seguridad de sus casas, son un par de procesos típicos que pueden amenazar los intereses de los poderosos" (Davis y Cory, 1996:
73). Definitivamente, "hay diversos factores que contribuyen al riesgo social por amenazas naturales, incluyendo aquellos que están relacionados a cómo son manejadas las amenazas naturales por la región o la nación donde vivimos" (Dwyer et al., 2004: 4).

En consecuencia, resulta un claro contrasentido hablar simultáneamente de un incremento del desarrollo y de los desastres (Figura $\mathrm{N}^{\circ} 1$ ); para que se dé lo primero, se requiere que ciertas condiciones económicas, sociales, políticas e institucionales sean favorables para el crecimiento cualitativo del individuo y de la comunidad (progreso); estas, como condiciones estructurales de la vulnerabilidad, se expresarían, concomitantemente, en coyunturas propicias para el decrecimiento de los niveles de exposición e impacto ante eventos potencialmente peligrosos (condiciones seguras). Anderson \& Woodrow (1989) lo expresaron, breve pero evidente, cuando definieron el desarrollo como "la reducción de vulnerabilidades (o de riesgo) y el aumento de las capacidades de la sociedad" (Anderson \& Woodrow, 1989: 65), o tal como lo han demostrado Cuny (1983), Wilches (1998) y Lavell (1998; 2000), a través de sus trabajos particulares, los desastres son indicadores de insostenibilidad en los procesos de gestión del desarrollo y de la gestión ambiental.

No obstante, no necesariamente todas las situaciones de riesgo se materializan en desastres, ello depende precisamente de la incapacidad humana de reducir la intensidad del fenómeno hasta cero. La Figura $N^{\circ} 2$ ilustra esta situación, allí se presenta un modelo conceptual de la interacción, en función del tiempo, entre el crecimiento de la población y la generación de condiciones inseguras, y su expresión final en términos de riesgo y desastre; este último, como un momento espacio-temporal en el que los impactos sufridos por la ocurrencia de un evento extremo rebasa el nivel de preparación y la capacidad de respuesta y resiliencia de una comunidad. El desastre entonces, como expresión espacio-temporal de las iniquidades y vulnerabilidades, se deriva de las relaciones de poder de los diversos grupos sociales que conforman una sociedad determinada. Estos son, ante todo, eventos socioculturales cuya materialización es el resultado de la construcción so- 
cial del riesgo. Por tanto, su reducción efectiva y progresiva depende de la incorporación de estos conceptos en todas y cada una de las políticas sectoriales y de planificación del desarrollo formuladas; en especial, de aquellas que definen las condiciones de pobreza, exclusión y marginalidad de las poblaciones y las hacen altamente vulnerables a agentes externos, y no solamente en los casos de reconstrucción posdesastre, como desafortunadamente se ha venido realizando.

América Latina desafortunadamente muestra en demasía los resultados de los desastres; las cifras de daños alcanzados para el período 1986-2006, por eventos naturales de diversa índole, son dramáticas y muestran la debilidad generalizada de una política de prevención de riesgos. La región, incluido el Caribe, reportó en estas dos décadas 88 terremotos, 400 inundaciones, 42 sequías, 65 deslizamientos, 3 tsunamis, 49 erupciones volcánicas y 256 fenómenos hidrometeorológicos. Los costos estimados por los daños dejados por estos son del orden de US\$ 71.820.650 millones, el número de muertos reportado fue de 385.021, los heridos alcanzaron la cifra de 2.311.161, las familias que quedaron sin vivienda son aproximadamente 6.949.798 y el número el total de afectados fue de 105.501.397 personas $^{5}$ (CRID, 2007).

\footnotetext{
5 A pesar de lo revelador de las cifras, se relacionan aquí únicamente los daños directos dejados por los eventos y reportados oficialmente; quedan de lado aquellos de comunidades al margen de la institucionalidad cuyas situaciones de desastre, posterior al evento, no alcanzan a incidir en la percepción colectiva (por cuanto no tenían nada que perder) y todo lo intangible asociado a los costos familiares, sociales, políticos, institucionales, e incluso médicos y de salud pública (como el costo de recuperación de heridos y mutilados y su reorientación productiva -si se llegare a hacer- o las condiciones postraumáticas de los individuos y su costos laborales; por ejemplo). No obstante, desafortunadamente el desastre continúa siendo lo que nos convoca, el que dispara sensibilidades, provoca solidaridad y canaliza recursos y voluntades; no ocurre lo propio con las actividades de gestión del riesgo, más efectivas, menos costosas, pero a su vez de menor impacto político, institucional, social y cultural.
}

Condiciones dinámicas que definen la interacción entre el desarrollo y los desastres

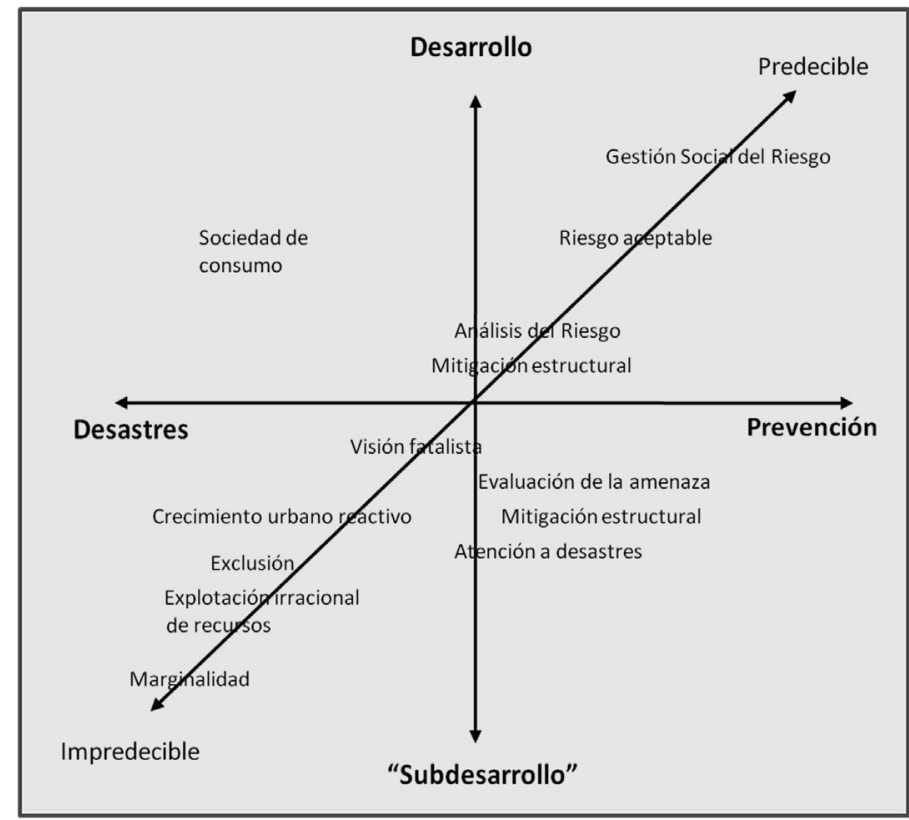

Fuente: Elaboración propia. 
Figura $\mathrm{N}^{\circ} 2$

Generación de riesgo y desastre como producto social

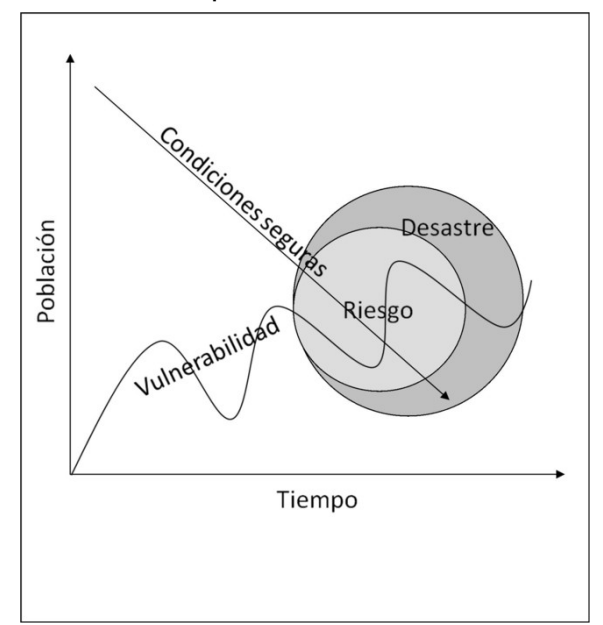

Fuente: Elaboración propia.

Generar desarrollo para prevenir y reducir los riesgos no es centrar las acciones en las amenazas o en el mismo riesgo, como algo instrumental, sino en las circunstancias particulares que hacen vulnerable a la población; es trabajar por ello incluso antes de la aparición de la misma amenaza, de tal forma que si esta llegare a presentarse, las condiciones inherentes al modelo de desarrollo y a su implementación local no producirían elevados niveles de exposición o fragilidad de las comunidades" analizar la vulnerabilidad de las estructuras, es necesario descifrar la estructura de la vulnerabilidad" (Chaparro y Renard, 2005: 23). Caso contrario, seguirá desafortunadamente ocurriendo la constante en los países subdesarrollados, de que cuando se evidencia el riesgo, son un hecho ya, prácticamente inmodificable, las condiciones estructurales y coyunturales que definen la vulnerabilidad, por cuanto los diversos actores económicos y políticos (algunos incluso responsables de

\footnotetext{
6 Recuérdese que lo que genera pérdidas en sí, no es la ocurrencia del evento amenazante (inherente, en este caso, a una dinámica natural), sino los niveles de exposición y vulnerabilidad de las comunidades asociados exclusivamente a condiciones antrópicas (sociales, políticas, económicas, entre otras).
}

la generación de las condiciones de vulnerabilidad) no están dispuestos a asumir los costos económicos de la corrección (sin lugar a duda, y demostrado ya, menores frente al escenario de continuar sin modificaciones $y$ esperar a que el desastre no ocurra).

Esta situación claramente se expresó en el salón que vio tomar forma a la Conferencia Mundial sobre la Reducción de los Desastres (ONU y EIRD, 2005), cuando se afirmó, textualmente, en el numeral 4 del literal A (EI reto de los desastres), que "hoy la comunidad internacional es consciente de que los esfuerzos de reducción del riesgo de desastre deben integrarse sistemáticamente en las políticas, los planes y los programas de desarrollo sostenible y reducción de la pobreza y recibir el apoyo de la cooperación y la asociación a nivel bilateral, regional e internacional. El desarrollo sostenible, la reducción de la pobreza, el buen gobierno y la reducción de los riesgos de desastre son objetivos que se refuerzan mutuamente. Para poder hacer frente a los desafíos, es preciso redoblar los esfuerzos por dotar a las comunidades y los países de la capacidad necesaria para controlar el riesgo y reducirlo. Este enfoque se ha de considerar un elemento importante para el logro de los objetivos de desarrollo internacionalmente acordados, incluidos los de la Declaración del Milenio" (ONE \& EIRD, 2005: 2).

En igual medida, y en oposición a interpretaciones mecanicistas del riesgo y del mismo desarrollo, después de haber sufrido un evento destructivo no se trata, como expresan algunos, de volver a las condiciones tenidas en las comunidades anteriores al evento, puesto que ellas precisamente fueron las que construyeron la vulnerabilidad de la población; de lo que realmente se trata, una vez pasadas las etapas de emergencia (rescate y atención) y rehabilitación inicial, es que las decisiones y acciones implementadas, en la fase de reconstrucción, se sustenten en la modificación estructural de aquellas condiciones que hicieron vulnerable a la población; es decir, estamos hablando de verdaderas acciones de desarrollo o como el mismo Lavell (2008) expresa, reconstrucción con transformación.

En conclusión, desde la cadena de concepciones-acciones, planteada por el 
desarrollo, que va desde las visiones de desarrollo (ideales), pasando por los sistemas institucionales y los modelos (Estado y sociedad), hasta su misma instrumentalización (planes, programas y proyectos sectoriales), puede ampliarse o reducirse la vulnerabilidad en cada etapa de su progresión. Así, modelos de desarrollo y su propia implementación, en un proceso consciente o inconsciente, pueden incrementar las vulnerabilidades de las comunidades, y en consecuencia sus riesgos. No obstante, conscientemente es posible lograr, con una cuidadosa planeación, la reacción opuesta reduciendo la vulnerabilidad de las poblaciones. Siguiendo el hilo argumentativo expuesto por Lavell (2008), es pasar de una gestión compensatoria (correctiva) a una gestión prospectiva, no solo del riesgo, sino del desarrollo; no se trata de reparar las imperfecciones que se han ido consolidando, consuetudinaria y firmemente, en la implementación del modelo, sino en crear, orgánicamente, condiciones presentes y futuras para que dichas fallas no se sigan dando. En últimas, se trata de tener conciencia que así como las acciones del hombre configuran una construcción social del riesgo, estas mismas pueden garantizar también una construcción social del desarrollo, a favor de la reducción de desastres.

\section{La Gestión Social del Riesgo, un camino aún por afianzar}

Reconociendo la necesidad de asumir no solo una interpretación integral del riesgo, sino la formulación de acciones estratégicas que permitan reducir estructuralmente los factores que hacen vulnerables a las comunidades, se ha venido planteando, desde diversos sectores públicos y académicos, la formulación de una política de gestión de riesgos. En general, la literatura especializada habla de gestión de riesgos y gestión de desastres como sinónimos, queriendo expresar con estos, el proceso mediante el cual se pretende identificar, evaluar, controlar y/o reducir los potenciales efectos de eventos adversos para el hombre.

Sin embargo, en estricto sentido no denotan lo mismo; la gestión de desastres parte de la situación de desastre y de cómo actuar a partir de ella; es decir, conceptual y operativamente su núcleo fundamental está vinculado con una situación posevento, donde lo que se busca es la implementación de ciertas prácticas del control de daños a favor del sistema existente y el retorno a la normalidad preexistente al evento destructor; incluso esta interpretación reconoce, así sea de forma implícita, como un hecho concomitante a la amenaza, el desastre; cuando este realmente está en función de la incapacidad humana de reducir la vulnerabilidad de la población hasta los niveles que las pérdidas sean aceptables, asumibles y asimilables por la sociedad en su conjunto y por la comunidades específicamente impactadas y no por la ocurrencia misma del evento en particular. En contraste, la gestión del riesgo pretende centrar todos sus esfuerzos en aquellos elementos generadores de condiciones de vulnerabilidad que exponen a las comunidades a situaciones de riesgo y que de no intervenir efectivamente sobre ellas, podrían, consiguientemente, conducir a desastres; esta se articula entonces, a evaluaciones preevento.

Arteaga (2006) define la gestión del riesgo como un "sistema de políticas, procedimientos y prácticas de gestión destinados a la tarea de identificar, analizar, evaluar y tratar de controlar los riesgos" (Arteaga, 2006: 3). Para él, administrar el riesgo es identificar y estar preparados para lo que pueda suceder; se trata de tomar acciones destinadas a eludir, mitigar y reducir los elementos expuestos a amenazas, en lugar de reaccionar después de que un evento ya haya ocurrido e incurrir en los costos que implican recuperar una situación.

Wilches (1998) habla de Gestión de la Reducción del Riesgo y afirma que esta debe ser considerada, en su esencia, como un componente intrínseco y esencial de la gestión del desarrollo y del desarrollo territorial y ambiental. Kohler et al. (2004) coinciden con este último, al considerar la gestión de riesgo de desastres naturales como una importante tarea transversal de la cooperación al desarrollo. Afirman que por ello, esta es objeto de diferentes áreas políticas y de trabajo (política interior, protección ambiental, agricultura, planificación nacional y regional, sector de la construcción, planificación del uso de la tierra, entre otras). 
Para Dwyer et al. (2004), el manejo del riesgo es el proceso de tratar los posibles resultados de un evento incierto, y que, tradicionalmente, involucra cuatro pasos: "mitigación, preparación, respuesta y recuperación". Los primeros dos generalmente se refieren a las acciones o medidas tomadas previamente a un impacto, mientras los últimos dos pasos involucran las acciones posteriores al impacto.

Otros como el BID (2007), sin llegar a plantear abiertamente una definición, relacionan, dentro de la cadena de actuaciones frente a los riesgos naturales, las medidas de prevención, tanto estructurales como no estructurales; el papel de la predicción a corto, medio y largo plazo; los agentes implicados en los sistemas de alerta; la necesaria educación del comportamiento frente al riesgo así como algunos aspectos relativos a la legislación y sistemas de seguros en relación con los riesgos naturales.

Lavell y Franco (1996) establecen una de las concepciones más integrales cuando afirman que "un sistema de gestión de riesgos se presenta como una organización abierta, dinámica y funcional de instituciones y su conjunto de orientaciones, normas, recursos, programas y actividades de carácter técnicocientífico, de planificación, de preparación para emergencias y de participación de la comunidad, y su objetivo la incorporación de la gestión de riesgos en la cultura y en el desarrollo económico y social de las comunidades" (Lavell y Franco, 1996: 11). Ramírez y Cardona (1996) coinciden totalmente con el SNPAD de Colombia, al retomar su concepción de la gestión de riesgos; para ellos esta es "el planeamiento y aplicación de medidas orientadas a impedir o reducir los efectos adversos de fenómenos peligrosos sobre la población, los bienes y servicios y el ambiente. Son acciones integradas de reducción de riesgos, de preparación para la atención de emergencias y recuperación posdesastre de poblaciones eventualmente afectadas" (Ramírez y Cardona, 1996: 11).

Una Gestión Social del Riesgo (GSR), entonces, se puede entender como el proceso institucional y social mediante el cual, en sentido horizontal y vertical, se articulan una serie de políticas, actores, estrategias, instrumentos y acciones que buscan eliminar, estructuralmente (prevenir), y mitigar y reducir, coyunturalmente, los elementos y niveles de exposición de las comunidades frente a aquellos eventos potencialmente destructores, a la vez que incrementar su capacidad de respuesta, ajuste y recuperación, frente a los efectos adversos de ellas. La GSR por tanto, implica el recopilar y sistematizar la información mínima que permita conocer el riesgo futuro al que se expondrá la población (dinámica y evolución de amenazas y factores y niveles de vulnerabilidad), crear los escenarios y condiciones propicias para la intervención y transformación social de las vulnerabilidades, diseñar las estrategias que garanticen la atención oportuna y eficiente en la emergencia (planes y programas) y prever las reservas (financieras, sociales e institucionales) que permitan la supervivencia en la situación de emergencia y/o desastre, y su reconstrucción, rehabilitación y recuperación, posterior a la crisis.

La GSR no es solo la reducción mecánica del riesgo, es, ante todo, el reconocimiento y la concientización social, de que ciertas prácticas económicas, políticas, institucionales, sociales y culturales, configuran escenarios desequilibrados, excluyentes e inequitativos que exponen de forma diferencial a la población ante eventos potencialmente destructores y vulneran, limitan o reducen, para el caso de los más frágiles, su capacidad de afrontarlos, asimilarlos y superarlos. La GSR exige espacios de convergencia y concertación social e institucional que permitan incorporar los diferentes estratos socioeconómicos, los diversos niveles de gestión y actuación pública y territorial y los disímiles sectores de interés y opinión, en la comprensión de cómo se construye un riesgo social y los niveles de responsabilidad y corresponsabilidad social que tiene cada uno frente a ello. La GSR, entonces, no es simplemente una respuesta mecánica, la de reducir la vulnerabilidad, sino la búsqueda de acuerdos sociales y políticos que garanticen evitar los niveles de exposición inicial de las comunidades ante eventos amenazantes, incrementar los niveles de bienestar de las comunidades marginadas, generar equidad e inclusión para los excluidos y capacidad de homeostasis y resiliencia, para todos, ante los impactos de potenciales eventos destructores. Este proceso, en tanto que participativo, concertado e 
integral, exige la configuración colectiva de escenarios de futuro, donde los niveles de bienestar de las comunidades menos beneficiadas se incrementen logrando estándares de desarrollo importantes, en comparación con los más favorecidos y reduciendo en consecuencia la posibilidad de desastres de alto valor socioeconómico.

Hacemos hincapié en la necesidad de abordar la prevención, atención y recuperación como un todo, rebasando una actitud estrictamente pasiva o reactiva y atacando los elementos que se consideran estructuralmente generadores de vulnerabilidades; ello implica superar el ámbito eminentemente técnico para acometer espacios y escenarios de la política, la comunicación y los medios masivos, la cultura y la sociedad (educación, vivienda, empleo, entre otros). Se habla entonces, como ya se planteó, de actuar incluso antes de la amenaza; es identificar las condiciones naturales, sociales, políticas, económicas, culturales e institucionales que convergen para configurar situaciones amenazantes y vulnerables, más que eventos aislados que en un momento determinado se disparan y configuran amenaza. Reconociendo y discriminando, en cada uno de los momentos de este proceso, obligaciones y compromisos de los diversos actores que componen la sociedad, ya que ello, además de deslindar responsabilidades, ayuda en la definición de estrategias, acciones y alcances, a la vez que permite identificar las distintas interacciones, positivas y negativas, que se tejen entre ellos, así como identificar los posibles puntos críticos a surgir en su implementación (Cuadro $\mathrm{N}^{\circ} 1$ ).

\section{Momentos y acciones de la GSR}

Con la aplicación de los principios y acciones de atención a heridos en situaciones de guerra ${ }^{7}$, a escenarios de afectación a civiles, se identificó la importancia de reconocer tres momentos en este proceso: Antes, Durante y Después. Con ello se buscó reconocer y contextualizar la dimensión temporal del hecho; de una parte, la particularidad de

\footnotetext{
7 Orígenes de la Cruz Roja, como posteriormente, casi un siglo después, de la misma Defensa Civil.
}

cada uno de los momentos que exige acciones puntuales y diferenciadas, pero a la vez, su concatenación y causalidad que establece una condición dinámica y requiere un tratamiento integral, coherente, cíclico y permanente. Ello ha establecido ya una importante experiencia en el diseño de estrategias y acciones en la prevención, atención o recuperación, según cada caso. La GSR se inscribe en esta lógica y retoma estos momentos.

El Antes, como su nombre lo indica, es la etapa anterior a la ocurrencia del evento y como tal implica la conciencia colectiva del reconocimiento de un riesgo potencial al que se está expuesto, y consecuentemente, el diseño, implementación y evaluación de medidas que permitan prevenir, reducir o prepararse ante los impactos generados por la eventual materialización de este. Es el momento en el cual se puede prevenir la exposición y reducir los niveles de vulnerabilidad y riesgos a los que está expuesta la población y de allí su importancia y trascendencia. Incorpora acciones correctivas como prospectivas; las primeras buscan corregir situaciones de riesgo ya configuradas, y las segundas, evitar, estructuralmente, que en el futuro se presenten condiciones de exposición de las comunidades ante nuevas amenazas o a las ya existentes.

La prevención comprende la planificación y ejecución de medidas y acciones que pretenden evitar o impedir que se presente un fenómeno potencialmente destructivo (cuando ello es posible) o para evitar los niveles de exposición, ante los ya existentes (evadir el probable impacto sobre la población, sus bienes y servicios y su ambiente soporte).

La mitigación es el reconocimiento de que no es posible evitar completamente la exposición ante el evento potencialmente destructor, y se es, en consecuencia, en cierta medida vulnerable ante este; es decir, es aceptar que no es posible llevar hasta cero el nivel de riesgo y consiguientemente la opción es reducirlo para convivir con este. La mitigación, entonces, involucra las medidas y acciones que buscan reducir la vulnerabilidad de la población y sus bienes y servicios, así como atenuar el posible impacto a sufrir por ellos ante la ocurrencia del evento destructor. 


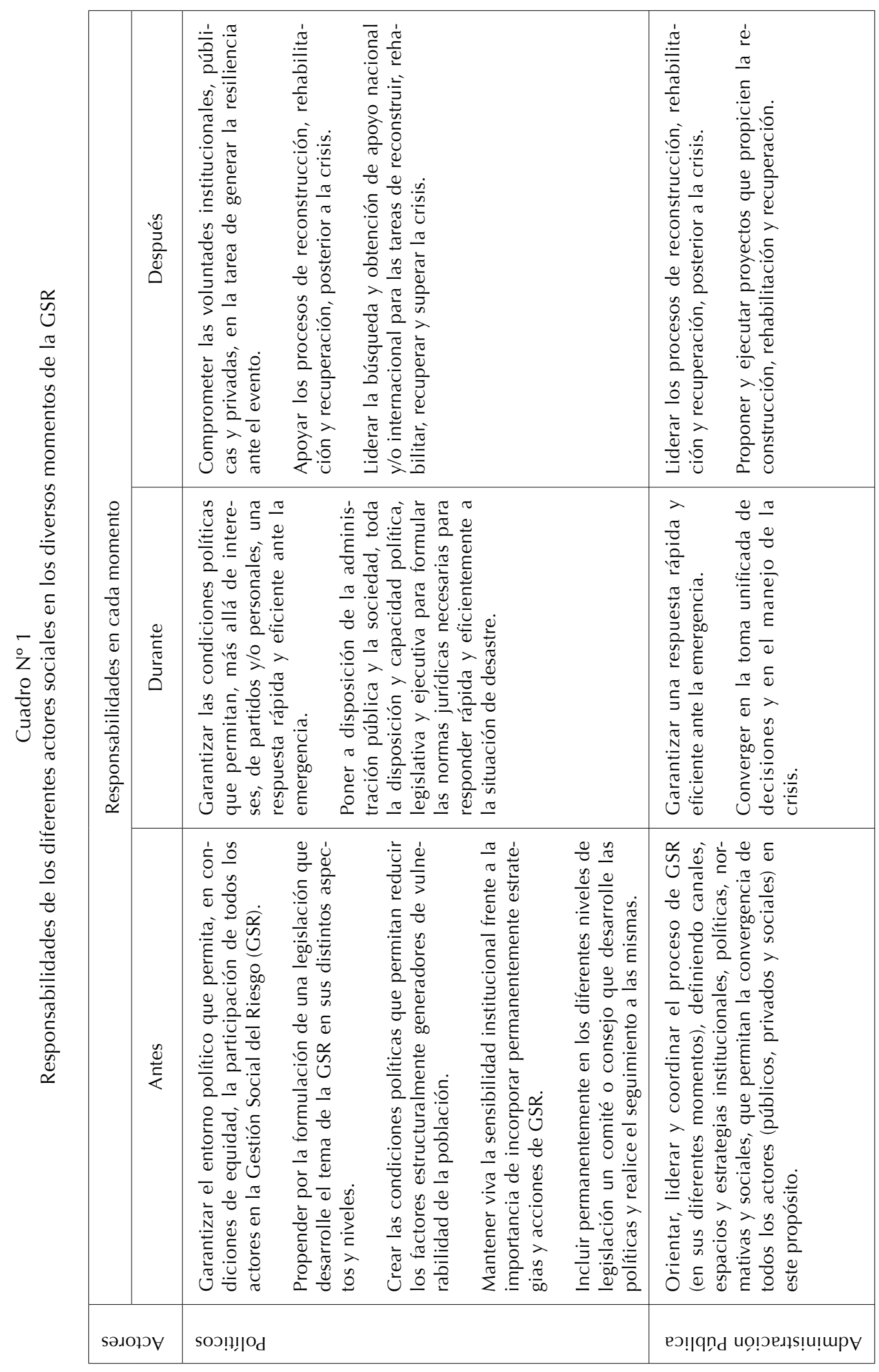




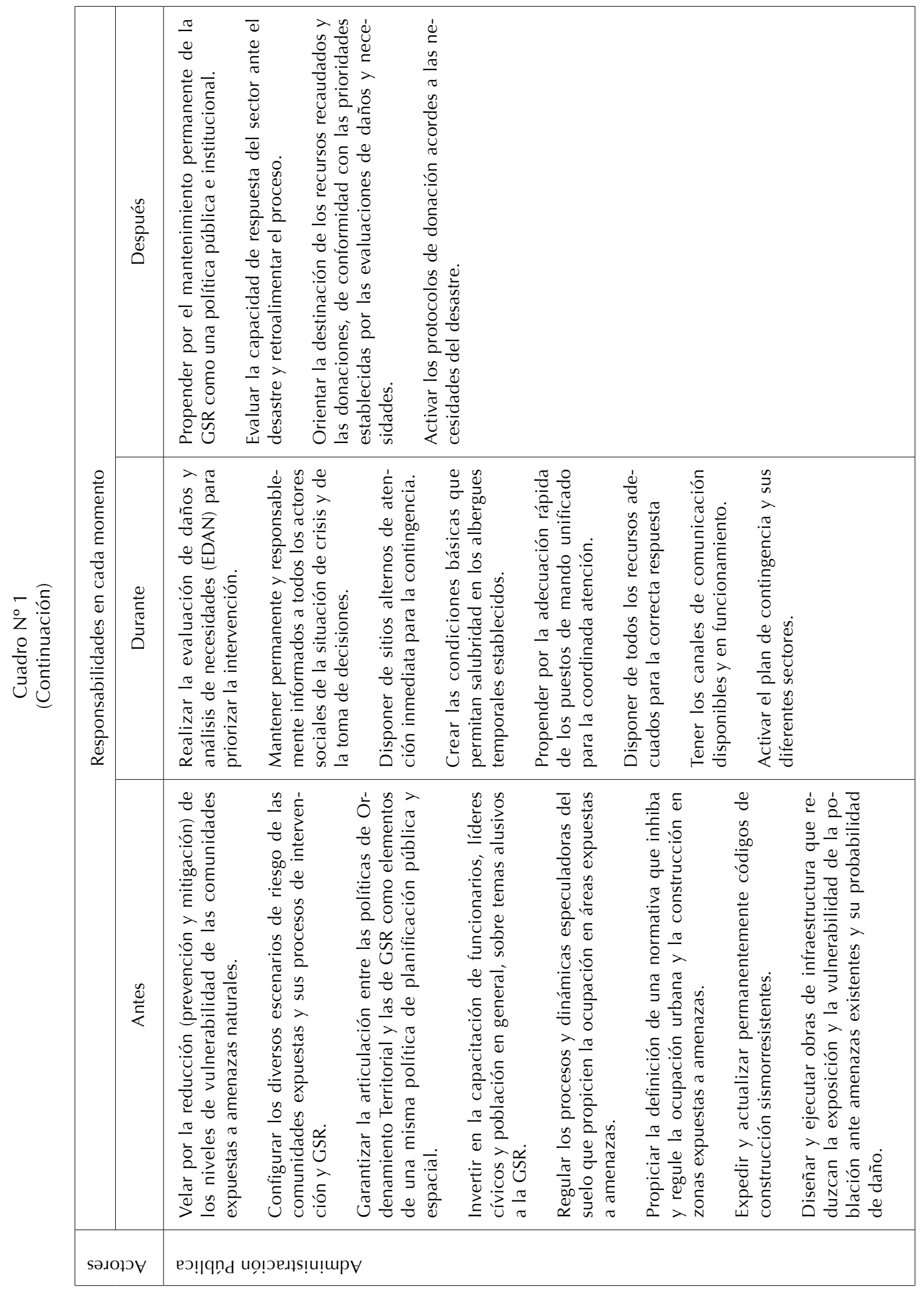




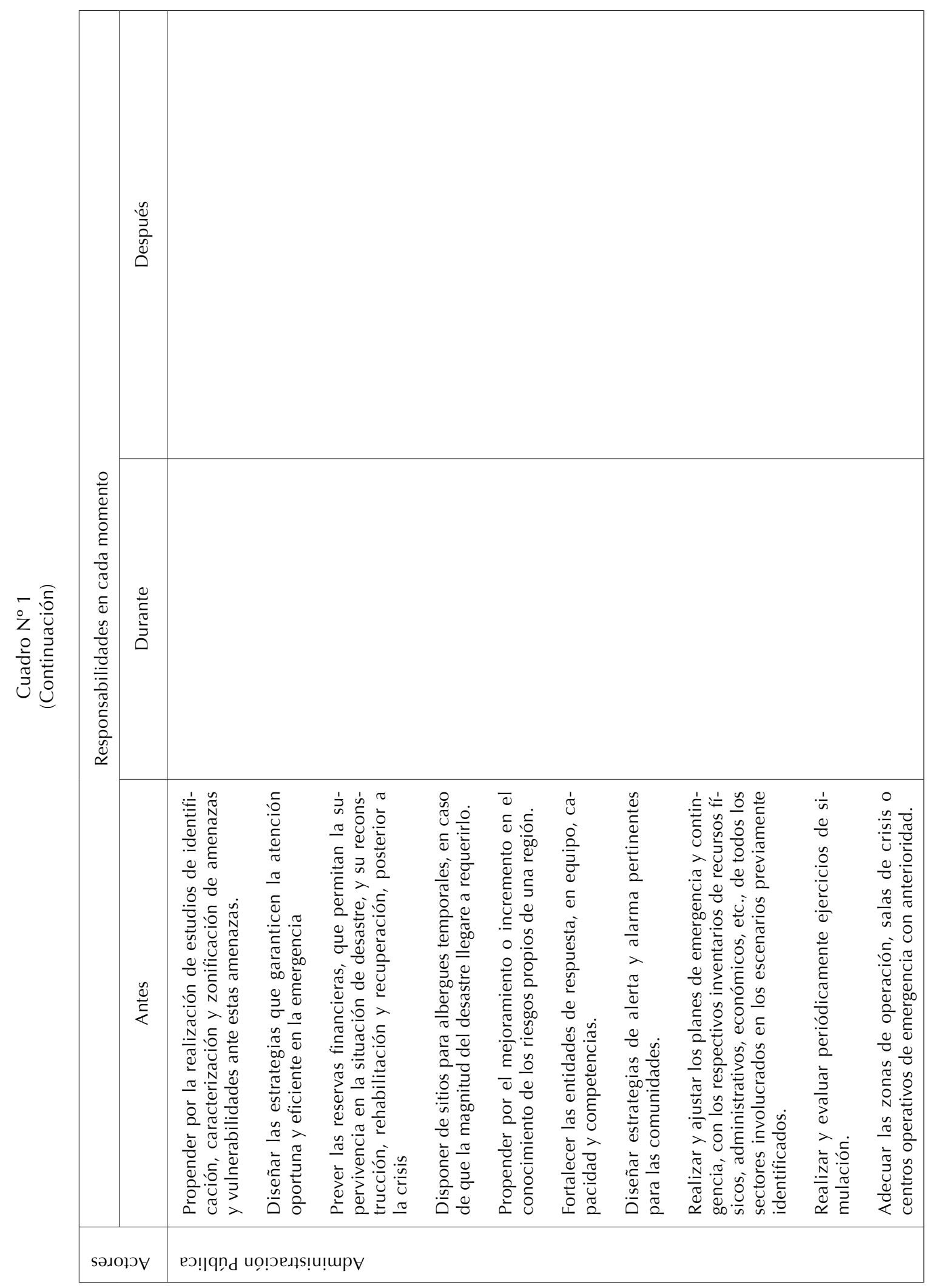




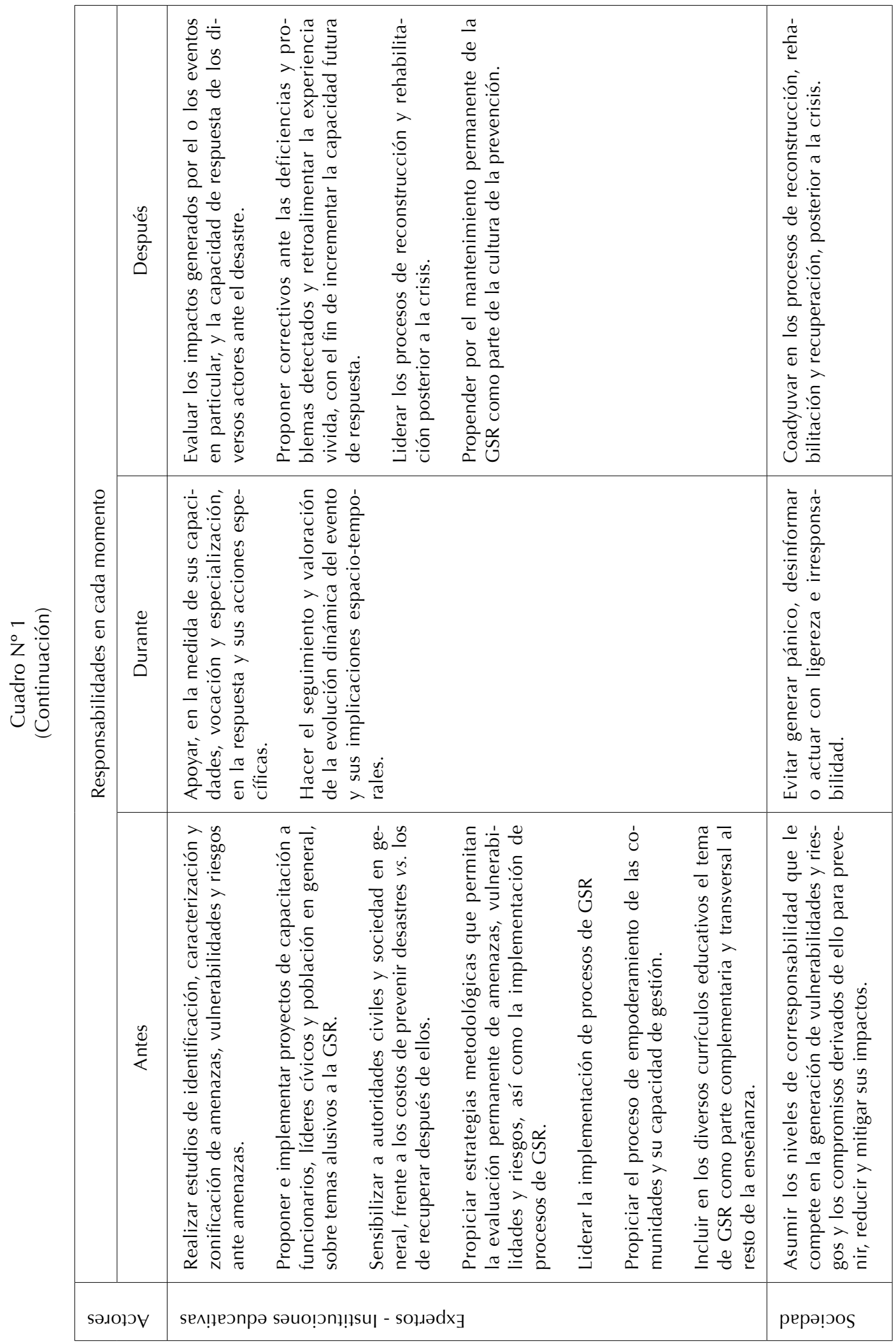




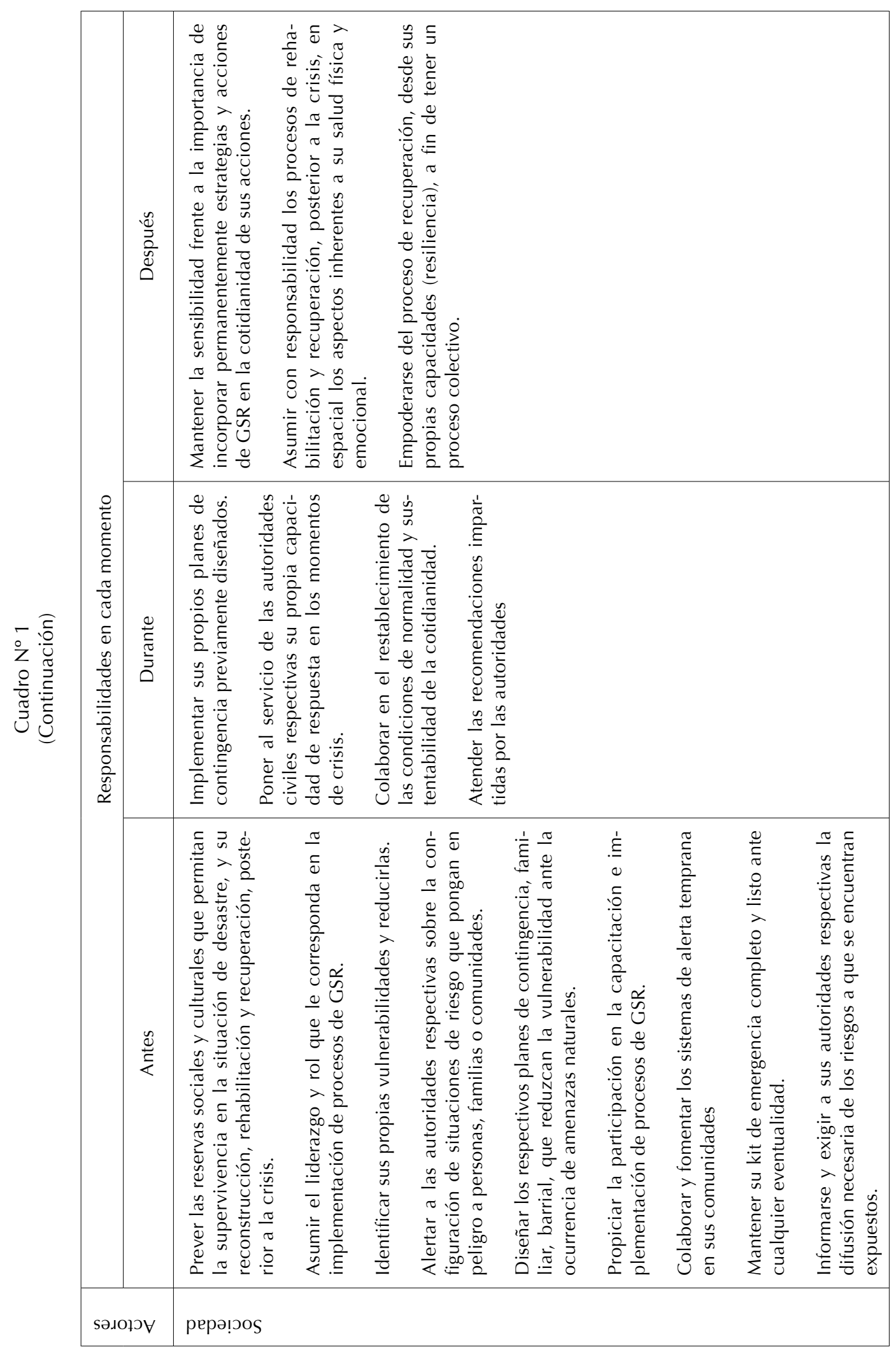




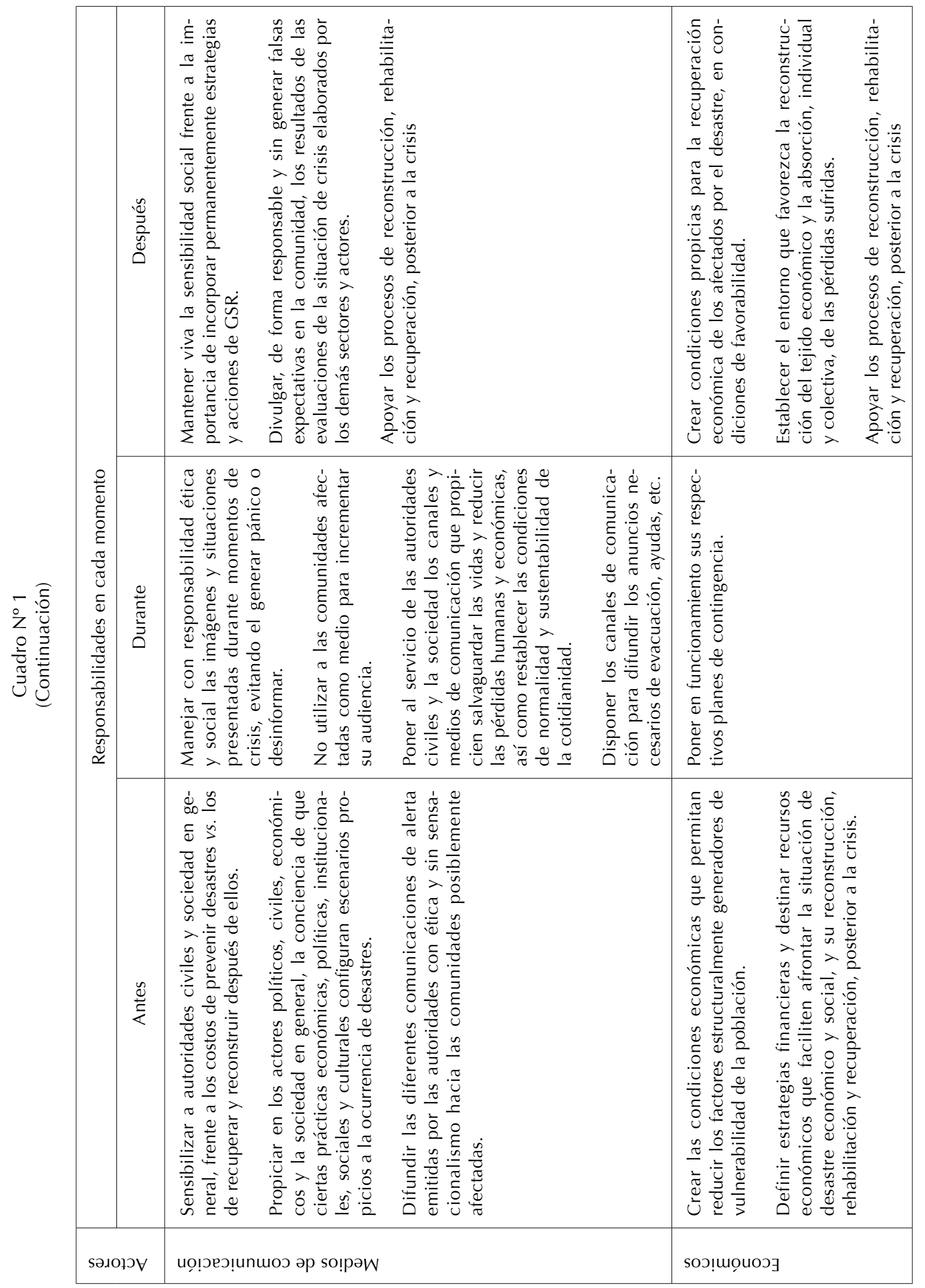




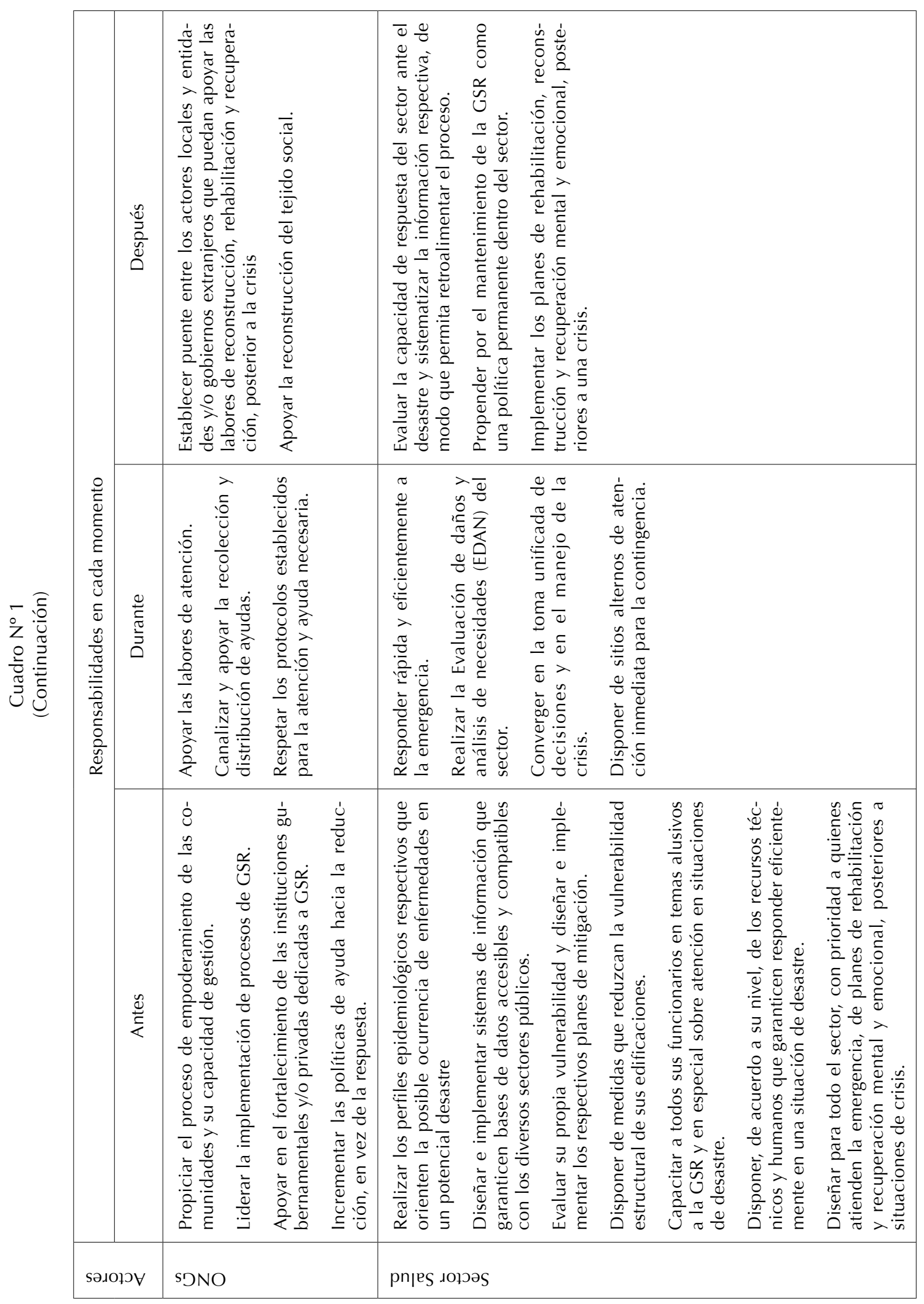




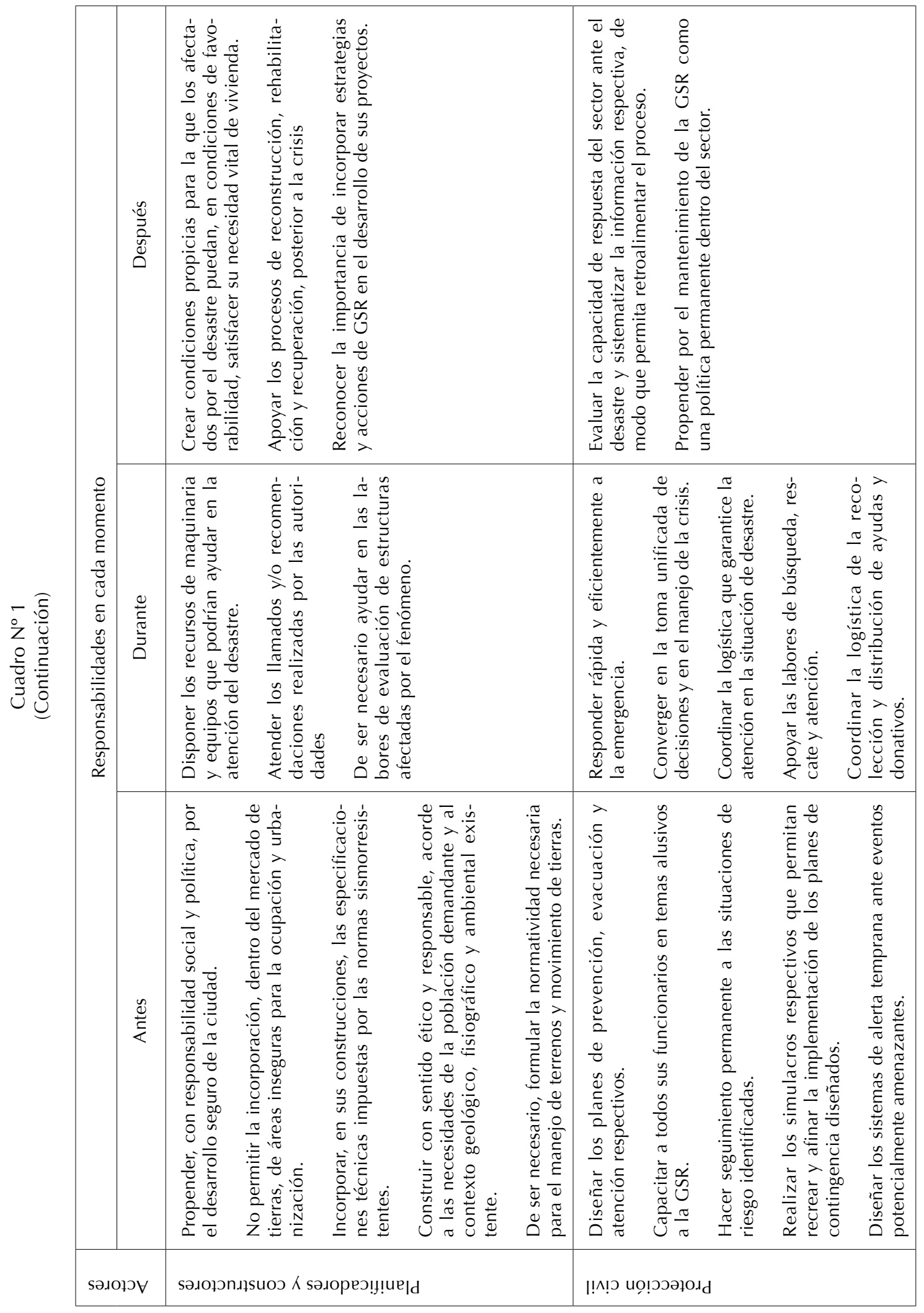


La preparación involucra todas aquellas medidas cuyo objetivo es organizar y facilitar los operativos, en caso de emergencia $y / o$ desastre, para el efectivo y oportuno aviso, las labores de salvamento, así como la posterior rehabilitación de la población. La preparación se lleva a cabo mediante la organización y planificación de las acciones de alerta, evacuación, búsqueda, rescate, socorro y asistencia, que deben realizarse en caso de emergencia y las iniciales de rehabilitación que garanticen la estabilización de los sistemas operativos y las edificaciones.

El durante es el momento mismo de ocurrencia del evento; es allí cuando deben hacerse efectivos los Planes de contingencia, entendidos como los procedimientos operativos específicos y preestablecidos, de alerta, coordinación, movilización y respuesta ante la manifestación del evento y sus probables consecuencias.

La respuesta corresponde a la ejecución de las acciones previstas en la etapa de Preparación e implica la reacción inmediata para la atención oportuna de la población. Existen divergencias frente a la duración de esta etapa, probablemente ello dependa de la intensidad e impacto alcanzados por el evento y el paso de una situación de emergencia a una de desastre. En el primer escenario la respuesta implica la alerta y evacuación (si Ilegara ser el caso); en el segundo, además de estas dos, estarían las de búsqueda, rescate, socorro y asistencia. Independientemente que se alcance un nivel u otro, la preparación debe contemplar ambos escenarios y diseñar estrategias y acciones que garanticen capacidad efectiva de respuesta y atención, de modo que se salvaguarden la mayor cantidad de vidas posibles en los momentos de búsqueda, rescate, socorro y asistencia, si se llegaren a necesitar, así como reducir el sufrimiento de las personas afectadas.

Se entiende por después, al tiempo posterior a la ocurrencia del evento destructor y puede durar, dependiendo de la magnitud alcanzada por el desastre, desde días hasta años. Este momento de recuperación es el complejo proceso de restablecimiento de condiciones adecuadas y sostenibles de vida mediante la Rehabilitación y Reconstrucción del área afectada, los bienes y servicios in- terrumpidos o deteriorados y la reactivación o impulso del desarrollo económico y social de la comunidad. Mientras que la Rehabilitación implica las acciones más inmediatas para restablecer las condiciones cotidianas de la población afectada directamente por el "desastre", más vinculadas con obras físicas; la Reconstrucción es un proceso de más largo plazo, involucra acciones de mayor cobertura temática ${ }^{8}$ y espacio-temporal de la población, abarcando incluso aquella que fue indirectamente afectada por el evento. Todas estas acciones definen la Resiliencia Social ante los desastres, o la capacidad de absorber y recuperarse de los efectos negativos generados por estos.

\section{El carácter territorial de la GSR}

Retomando las definiciones de la COT (1992), SEDESOL (2004), SEMARNAT (2006), las mismas leyes, 388/97 de la legislación colombiana (Congreso de la República de Colombia, 1997) y General de Asentamientos Humanos del Gobierno Mexicano (DOF, 1976) y a autores como MacDonald \& Simioni (CEPAL, 1999), Guidiño (1993) y Massiris (1999), se puede concluir que el ordenamiento territorial, primero, es un problema ante todo geográfico, pero en especial atinente al hombre en función de su espacio (planeación territorial); segundo, involucra la optimización de recursos tanto naturales como sociales y la integración armónica (equilibrio dinámico) entre las condiciones naturales y las necesidades socioculturales (desarrollo sustentable); tercero, pretende la reducción de las disfuncionalidades espaciales y los desequilibrios socioeconómicos regionales y la articulación del territorio en los diferentes niveles de actuación (equidad regional); y cuarto, a pesar de ser una política pública (en cabeza del Estado), exige la convergencia de intereses culturales, económicos y políticos distintos; por tanto es participativa y proactiva.

Todo esto acerca directamente a la GSR, puesto que, si la concatenación de escalas espaciales (entre lo local, lo regional, lo nacio-

8 Física, económica y productiva, cultural, psicológica y emocional. 
nal y lo internacional), los hechos y procesos sociales, económicos y políticos, así como las condiciones específicas de los individuos, se materializan y expresan en el territorio; es en él en donde convergen las condiciones específicas de un entorno natural y cultural que definen tanto la amenaza como la exposición ante este fenómeno, que se expresa, en ese lugar y no en otro, y en las combinaciones e intensidades requeridas para causar, eventualmente, impactos específicos. Igualmente, la construcción de escenarios de futuro que propicien el incremento del bienestar de la población y la prevención y reducción del riesgo, necesariamente pasan por el territorio; es decir, la GSR necesariamente debe abordarse desde una perspectiva territorial, que incorpore las dimensiones, física, política y espacial.

Si bien es cierto que para el mundo urbanizado de este siglo uno de los recursos más escasos y costosos es el suelo, y que los hechos evidencian la cada vez mayor y más rápida concentración de población en estas áreas, también lo es que para un número mayor de personas, y por las razones anotadas, la ocupación del espacio al margen de procesos de planificación territorial propicia la construcción de condiciones proclives a vulnerabilidades y por lo regular, para nuestros países, excluye a los sectores más necesitados de condiciones favorables de habitabilidad y seguridad. Por otra parte, la tendencia reactiva de nuestra planificación territorial (a corregir más que a proponer o crear) y la también disociación con la GSR, hace que el abordaje de estas situaciones sea sectorial y no espacial ni holístico; la tradicional gestión de los desastres ha carecido de una visión territorial prospectiva y ha ido a la retaguardia de las situaciones, atendiendo, o en el mejor de los casos, corrigiendo. Se debe romper el círculo de que la planificación territorial crea condiciones de futuro al margen de la Gestión del Riesgo, que esta luego entra a corregir ${ }^{9}$, e integrarlos, desde un inicio, y desde una dimensión territorial, a la GSR.

Ello hace indispensable y prácticamente obligado, desde la planificación territorial,

9 Que se asume también como una política sectorial, no espacial. el definir políticas de uso y ocupación del suelo que reduzcan la posibilidad de configuración de situaciones de riesgo; es decir, que además de responder a las necesidades inmediatas, rebasen la coyuntura (acciones a corto, mediano y largo plazo); pero sobre todo, sean integrales y armónicas al territorio (que reconozcan e incorporen las posibilidades y restricciones de orden institucional, político y sociocultural y a su vez articulen los objetivos, metas y estrategias de los planes sectoriales con los de ocupación integral del territorio). No es deseable que continúen diseñándose las políticas sectoriales (en especial las económicas), al margen de las implicaciones, positivas o negativas, que estas tengan en la configuración de niveles de vulnerabilidad de las poblaciones. Se requiere, entonces, la convergencia y negociación entre actores distintos con circunscripciones territoriales diferentes, desde lo local hasta lo internacional.

Por tanto, la planificación territorial debe, con base en el conocimiento de las dinámicas físicas potencialmente destructivas y el comportamiento de las comunidades que ocupan esos espacios, hacer un esfuerzo por adelantarse a los cambios bruscos inducidos por estos eventos y predecir sus impactos, así como establecer espacios de actuación pública y ciudadana en las que las comunidades puedan crear escenarios concertados de futuro en los que sus niveles de exposición y daño se reduzcan potencialmente.

Si bien las acciones y tiempos de los momentos definidos tradicionalmente en la Gestión del Riesgo como en la Planeación Territorial, no son necesariamente y completamente coincidentes, sí es posible articular el Antes de la Gestión del Riesgo con las etapas del proceso de Planeación territorial ${ }^{10}$. La Figura $\mathrm{N}^{\circ} 3$ muestra como operativamente se pueden acoplar estas; allí se aprecia que resulta esencial construir un nivel de riesgo socialmente aceptable, que establece, en el marco de la severidad del riesgo y las con-

\footnotetext{
10 Nótese que de alguna forma las etapas del Durante y Después de la Gestión del Riesgo, están cubiertas en la fase de Formulación territorial, cuando se hace referencia a los planes de contingencia, rehabilitación y reconstrucción.
} 
diciones socioeconómicas particulares de cada comunidad, las pérdidas que determinado grupo está dispuesto o en capacidad de asumir, por cuanto considera imposible, inoportuno, innecesario, o excesivamente costosa, una intervención para su reducción. Con base en este supuesto, deben diseñarse los mínimos de seguridad que van a alimentar los diversos planes de prevención, mitigación y protección, e incluso los de la misma contingencia.

Retomando a Thomas (2008), se resalta en que definir una política eficaz de GSR en el contexto del ordenamiento del territorio demanda que las administraciones públicas reconozcan que:

a) Por la naturaleza del territorio los fenómenos potencialmente destructores siempre estarán presentes como algo concomitante a su carácter y funcionamiento, y las eventuales situaciones amenazantes aparecerán, temprano o tarde, y en menor o mayor grado. Es obligación, por tanto, permanecer alerta a la manifestación de indicadores y precursores de las amenazas.

b) Los fenómenos potencialmente destructores tienen una expresión espacial determinada; es necesario identificar tanto su génesis, como sus principales mecanismos funcionales para comprender su comportamiento, patrones espaciales y potenciales áreas de afectación.

c) Jamás se podrá estar suficiente o completamente preparado para la ocurrencia de un evento potencialmente destructor, por tanto se torna obligatorio el diseño de escenarios de riesgo que permitan la formulación de políticas de intervención y transformación, tanto de las causas estructurales de las vulnerabilidades, como de las condiciones vulnerables de la población expuesta a amenazas.

d) Las políticas de prevención y mitigación exigen la territorialización de las acciones y la articulación de los diversos niveles de actuación pública, y a partir de ellas, la definición sectorial de estrategias de intervención, de tal forma que lo sectorial materialice la propuesta espacial y no al revés. Igualmente, es necesario que los resultados obtenidos en la valoración de amenazas y riesgos (cartografía diagnóstica, tablas, estadísticas y análisis diversos) sean recogidos e incorporados en una política espacial de GSR.

e) Las situaciones de vulnerabilidad de las comunidades, se configuran por la combinación de las causas estructurales como de las condiciones vulnerables de la población. Sobre ambas es necesario incidir para reducir la vulnerabilidad.

En la mayoría de los casos es posible diseñar acciones que reduzcan los riesgos, vía vulnerabilidad. No obstante, por la naturaleza de los fenómenos que definen las amenazas es muy difícil actuar sobre ellos, máximo se pueden mitigar, en cambio la vulnerabilidad, y por ende el riesgo, sí se puede prevenir o reducir.

La gran mayoría, por no decir la totalidad de los llamados desastres, tanto naturales como antrópicos, responden más a condiciones socioculturales que físico-naturales, sobre las cuales es posible incidir a corto, mediano y largo plazo. De allí se desprende una importante dosis de responsabilidad política de las administraciones públicas en la generación, o no, de causas y condiciones vulnerables de la población y en el diseño e implementación de políticas de GSR que salvaguarden la vida de las personas expuestas a amenazas, máxime razón de ser de cualquier proceso de Gestión del Riesgo. Las políticas establecidas en este contexto deben ser estructurales y no coyunturales; es decir, deben rebasar la mirada paliativa y ser proactivas, reconociendo que deben barrer las distintas dimensiones que definen las situaciones de vulnerabilidad de las comunidades.

Ya que el territorio es dinámico, tanto en su dimensión físico-natural como sociocultural, este es un proceso permanente e iterativo; jamás se llega a un punto final, sino que demanda la definición de políticas, estrategias y acciones sostenibles en el espacio y en el tiempo.

En fin, en el mundo contemporáneo se hace evidente que la concepción, definición e implementación de una Gestión Social 


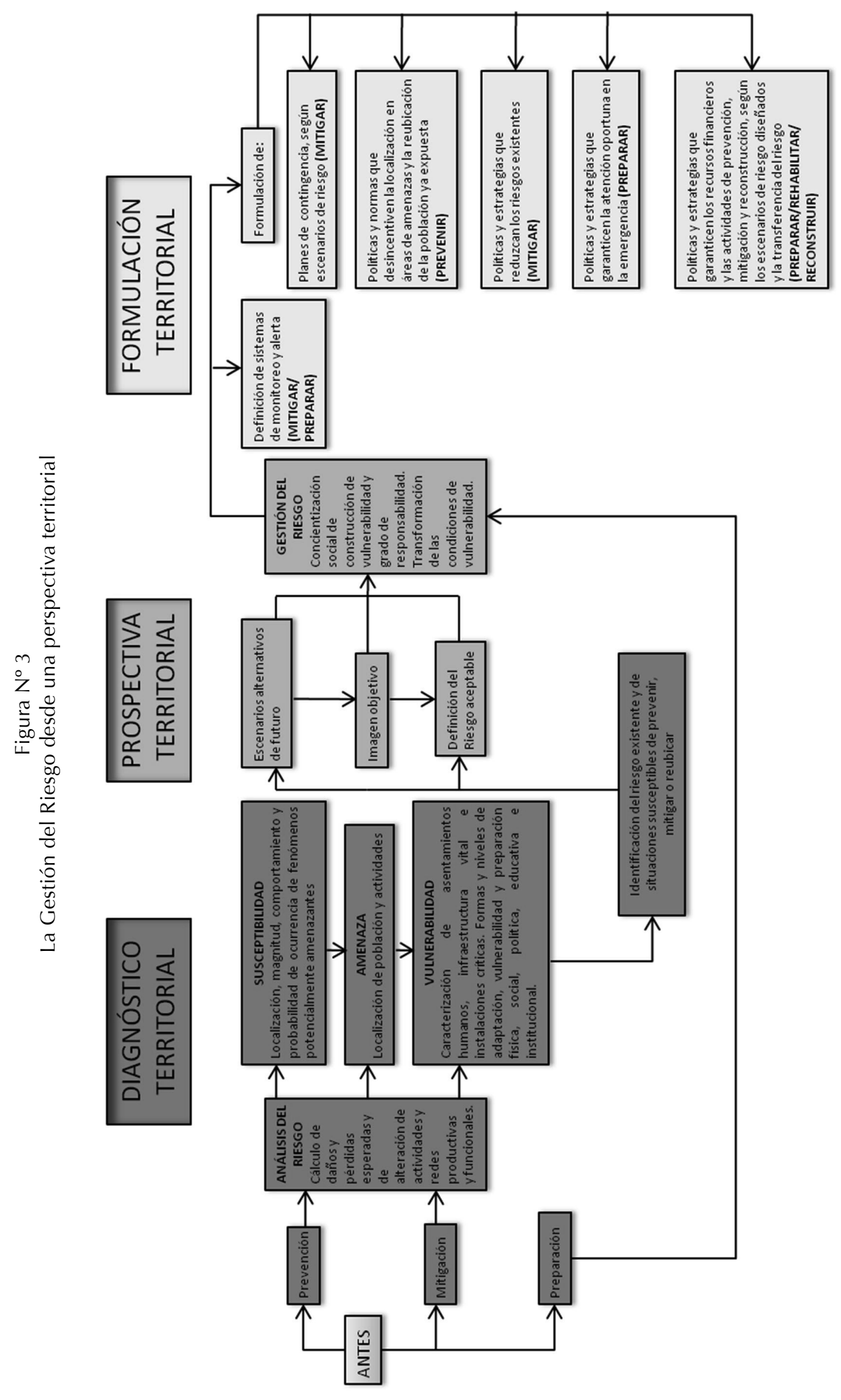

$\frac{0}{0}$
$\frac{.0}{0}$
$\frac{0}{0}$
$\frac{0}{0}$
$\frac{\pi}{0}$
$\frac{0}{0}$
$\frac{0}{4}$
00
$\frac{0}{0}$
$\frac{1}{3}$ 
del Riesgo se configura como una política necesaria y eficiente en la generación de condiciones estructurales de menor vulnerabilidad y reducción de factores y niveles de exposición de las comunidades ante eventos potencialmente destructores. En este punto no nos queda más que alinearnos con Rist et al. (1992), Romaña (1989) y Rahnema (1990), quienes relacionan interesantes y significativos casos que evidencian como, desde el sur, desde movimientos sociales de base, es posible restaurar la autonomía política, económica y social de las comunidades marginadas, de forma tal, que les permite reorganizar su existencia conforme a sus propios ideales, expectativas y necesidades, centrándose en sus particulares contextos y creatividad, para, a partir de sí y sus similares, satisfacer sus auténticos requerimientos y no aquellos impuestos por el desarrollo occidental; poniendo en su justo medio el papel de los agentes económicos y la acumulación de bienes materiales. Desde allí, la GSR se erige como posibilidad de allanar el camino en el que disfrutemos, no solo de mejores condiciones de bienestar, seguridad y habitabilidad, para todos, sino de acercarnos a otras realidades alternas de desarrollo que legitimen y potencien la condición social y cultural de los pueblos. El otro camino, el de acomodarse en la estructura actual, privilegiando la producción de bienes prioritarios para los menos favorecidos (Comeliau, 1992), conlleva la inmensa dificultad política de que aquellos que ostentan el poder no están interesados en el cambio, así pregonen lo contrario, y los que quieren el cambio no tienen los medios necesarios para imponerlo (Rist, 2002). Entonces, la ruta ya está delineada, ojalá caminemos con la seguridad y firmeza de reconocer y valorar nuestro pasado, tanto, como para modificar en nuestro presente lo que haya que hacerse para gozar de un mejor futuro para todos, pero en especial, para aquellos que histórica y tradicionalmente han estado marginados, excluidos y segregados del deseado, y nunca saboreado, desarrollo, y sufrido el embate de los equívocamente llamados desastres naturales.

\section{Referencias bibliográficas}

ANDERSON, M. \& WOODROW, P. Rising from the ashes: development strategies in times of disaster. Boulder: Westview Press, 1989.

ARTEAGA, D. De la gestión de desastres a la gestión de riesgo-análisis de la problemática existente en los sistemas de respuesta a desastres. Revista Cities on Volcanoes, 2006, № 4, p. 23-27.

BANCO INTERAMERICANO DE DESARROLLO (BID). Disaster Risk Management IDB Activities. Washington: BID, 2007.

BANCO MUNDIAL. Informe sobre el desarrollo mundial. New York: Banco Mundial, 2000.

BLAIKIE, P.; CANON, T.; DAVIS, I. Y WISNER, B. Vulnerabilidad. El entorno social, político y económico de los desastres. Bogotá: La Red, 1996.

CALDERÓN, G. Construcción y reconstrucción del desastre. Ciudad de México: ediciones Plaza y Valdés, 2001.

CENTRO REGIONAL DE INFORMACIÓN SOBRE DESASTRES PARA AMÉRICA LATINA Y EL CARIBE (CRID). Proyecto fortalecimiento de un sistema de información municipal para la prevención de desastres en América Latina y el Caribe. San José: CRID, 2007. Disponible en Internet: http://www.crid.or.cr/crid/IDRC/ Proyecto\%20IDRC-CRID.pdf

CHAPARRO, E. y RENARD, M. (eds.). Elementos conceptuales para la prevención y reducción de daños originados por amenazas socionaturales. Santiago: CEPAL, ONU, GTZ, 2005.

COMELIAU, C. Les relations Nord-Sud. París, La décuverte, 1992.

COMISIÓN DE ORDENAMIENTO TERRITORIAL (COT). Boletín de ordenamiento territorial $N^{\circ} 3$. Bogotá: ed. IGAC, 1992.

COMISIÓN ECONÓMICA PARA AMÉRICA LATINA Y EL CARIBE (CEPAL). Estudio económico de América Latina 1949. Nueva York: ONU, 1951. 
COMISIÓN ECONÓMICA PARA AMÉRICA LATINA Y EL CARIBE (CEPAL). Consensos urbanos. Aportes del Plan de Acción Regional de América Latina y el Caribe sobre Asentamientos Humanos. Santiago: CEPAL, 1999.

COMISIÓN ECONÓMICA PARA AMÉRICA LATINA Y EL CARIBE (CEPAL) y BANCO INTERAMERICANO DE DESARROLLO (BID). La reducción de la vulnerabilidad frente a los desastres: un tema del desarrollo. Santiago: CEPAL, BID, 2000.

CONGRESO DE LA REPÚBLICA DE COLOMBIA. Ley 388 de Reforma Urbana. Bogotá: Ed. Congreso, 1997.

CUNY, F. Disasters and development. Oxford: University Press, 1983.

DAVIS, I. y CORY. A. Modelos de desarrollo y vulnerabilidad. En: MANSILLA, E. (ed.), Desastres, modelo para armar. Lima: La Red eds., 1996, p. 72-84.

DOF. Ley General de Asentamientos Humanos. Ciudad de México: DOF, 26 de mayo de 1976.

DWYER, A.; ZOPPOU, C.; NIELSEN, O.; DAY, S. \& ROBERTS, S. Quantifying social vulnerability: a methodology for identifying those at risk to natural hazards. Canberra: Geosciencie Australia, Australian Government, 2004.

ESCOBAR, A. La invención del Tercer Mundo. Construcción y deconstrucción del desarrollo. Bogotá: Ed. Norma, 1998.

ESTRATEGIA INTERNACIONAL PARA LA REDUCCIÓN DE DESASTRES (EIRD). LOS desastres naturales y el desarrollo sostenible: considerando los vínculos entre el desarrollo, el medio ambiente y los desastres naturales. Ginebra: EIRD, Documento base N 5, 2001.

GOODLAND, R.; DALY, H.; EL SERAFY, S. \& VON DROSTE, B. Medio ambiente y desarrollo sostenible. Más allá del Informe Brundtland. Madrid: Editorial Trotta S. A., Serie medio ambiente UNESCO, 1997.
GUIDIÑO, M. Innovaciones estratégicas para el ordenamiento territorial en la argentina. Revista Interamericana de Planificación, 1993, vol. XXVI, No 104, p. 11-28.

HEWITT, K. Daños ocultos y riesgos encubiertos: Haciendo visible el espacio social de los desastres. En: MANSILLA, E. (ed.). Desastres, modelo para armar. Lima: La Red eds., 1996, p. 11-29.

KOHLER, A.; JÜLICH, S. y BLOEMERTZ, L. Manual El análisis de riesgo. Una base para la gestión de riesgo de desastres naturales. Eschborn: GTZ, 2004.

LAVELL, A. Desastres y desarrollo: hacia un entendimiento de las formas de construcción social de un desastre. El caso de Mitch en Centroamérica. En: BID. Revista del desastre al desarrollo sostenible: huracán Mitch en Centroamérica. San José de Costa Rica: BID, CIDHS, 2000. Disponible en Internet: http://www.desenredando.org/ public/articulos/200/dvd(DyD2000_ mar_1_2002.pdf

LAVELL, A. Una visión de futuro: la gestión del riesgo. San José de Costa Rica: inédito, 2008.

LAVELL, A. y FRANCO, E. (eds.). Estado, sociedad y gestión de los desastres en América Latina. San José de Costa Rica: La Red, 1996.

LEWIS, A. The dual economy revisited. The Manchester School of Economic \& Social Studies, 1979, vol. 47, No 3, p. 211-229.

MASSIRIS, A. Ordenamiento territorial: experiencias internacionales y desarrollos conceptuales y legales realizados en Colombia. Perspectiva Geográfica, 1999, № 4, p. 7-75.

MORIN, E. El método. III. El conocimiento del conocimiento. Madrid: Ed. Cátedra, 1986.

NURKSE, R. Equilibrium and Growth in the World Economy. Massachusetts: Harvard University Press, 1961. 
ORGANIZACIÓN DE NACIONES UNIDAS (ONU) Y ESTRATEGIA INTERNACIONAL PARA LA REDUCCIÓN DE DESASTRES (EIRD). Marco de Acción de Hyogo para 2005-2015. Aumento de resiliencia de las naciones y las comunidades ante los desastres. Viena: ONU, EIRD, 2005.

QUARANTELLI, E. Desastres y catástrofes: condiciones y consecuencias para el desarrollo social. En: MANSILLA, E. (ed.). Desastres, modelo para armar. Ciudad: La Red eds., 1996, p. 30-43.

RAHNEMA, M. Swadhaya: the unknow, the peace-ful, the silent yet singing, Revolution of Indian. IFDA Dossier, 1990, N ${ }^{\circ}$ 75-76, p. 13-24.

RAMÍREZ, G. y CARDONA, O. El sistema nacional para la prevención y atención de desastres de Colombia. Revista Estado, sociedad y gestión de los desastres en América Latina, 1996, p. 255-308.

RIST, G.; RAHNEMA, M. \& ESTEVA, G. Le nord Perdu. Lausana: Editions d'En Bas, 1992.

RIST, G. El desarrollo: historia de una creencia occidental. Madrid: Los libros de la catarata, 2002.

ROMAÑA, A. L'économie autonome. Une alternative sociale en émergence. Interculture Montreal, 1989, vol. 22, No 3-4, p. 210.
SECRETARÍA DE DESARROLLO SOCIAL (SEDESOL). Guía metodológica para la elaboración de Atlas de Peligros Naturales a nivel de ciudad (Identificación y zonificación). Pachuca: Programa Hábitat, 2004.

SECRETARÍA DEL MEDIO AMBIENTE $Y$ DE LOS RECURSOS NATURALES (SEMARNAT). Manual del proceso del Ordenamiento Ecológico. Ciudad de México: SEMARNAT, 2006

SEN, A. Poverty and famines: an essay on entitlement and deprivation. Oxford: Clarendon Press, 1991.

SUSMAN, P.; O'KEEFE, P. \& WISNER, B. Global disasters, a radical interpretation. In: HEWITT, K. (ed.). The idea of calamity in a technocratic age. New York: Allen \& Unwin Inc., 1983, p. 264-283.

THOMAS, J. Propuesta metodológica para la evaluación de vulnerabilidad social ante amenazas naturales. Tesis Maestría en Desarrollo sustentable. Cali: Universidad del Valle, Colombia, 2008.

WILCHES, G. Auge, caída y levantada de Felipe Pinillo, mecánico y soldador o yo voy a correr el riesgo: guía de la red para la gestión local del riesgo. Quito: La Red, IT, 1998. 